53 (2021) pp. $45-59$

DOI: https://doi.org/10.33039/ami.2021.04.003

URL: https://ami.uni-eszterhazy.hu

\title{
English language learning by visualizing the literary content of a knowledge base in the three-dimensional space*
}

\author{
István Károly Boda ${ }^{a}$, Erzsébet Tóth ${ }^{b}$ \\ ${ }^{a}$ Debrecen Reformed Theological University, \\ Department of Mathematics and Informatics \\ boda.istvan@drhe.hu \\ ${ }^{b}$ University of Debrecen, Faculty of Informatics \\ toth.erzsebet@inf.unideb.hu \\ Submitted: January 9, 2021 \\ Accepted: April 7, 2021 \\ Published online: May 18, 2021
}

\begin{abstract}
In our paper we would like to present and visualize the details of the data structure and organization of our three-dimensional virtual library model (3DVLM). The current implementation of the model is based on the features of the three-dimensional virtual space of the MaxWhere Seminar System [23] which provides carefully arranged smartboards in the $3 \mathrm{D}$ space for hypertextbased content.

Keywords: Three-dimensional virtual library model (3DVLM), MaxWhere Seminar System, Callimachus and the Library of Alexandria, text-based English language learning
\end{abstract}

AMS Subject Classification: 68U05, 68U35, 68T05, 91E10, 91E40

\section{Introduction}

The overall aim of the three-dimensional virtual library model (3DVLM) is to provide for the library users selected verbal and multimedia content in the virtual $3 \mathrm{D}$

*This research was supported by the construction EFOP-3.6.3-VEKOP-16-2017-00002. The project was co-financed by the Hungarian Government and the European Social Fund. 
space (and in parallel in the hypertextual 2D space). In general, the 3DVLM can be considered as a human-computer interaction-based application in the framework of CogInfoCom research [1, 2] focusing on the efficient organization and visualization of the presented content in order to help preserve and transmit classical cultural heritage and to support autonomous and text-based English language learning [15].

The 3DVLM is intended to achieve two basic goals:

- first, giving a general introduction and overview of the classical heritage which the European culture is based on. In this respect, the users can have access to selected texts about Callimachus who was one of the most productive and influential Hellenistic scholar-poets of his age. In addition, the library contains selected literary texts by Callimachus and other prominent authors (e.g. epigrams, lyric poems, anecdotes etc.). Because an average user of the library may have difficulties in understanding the provided literary texts, the library provides the readers with supporting materials (e.g. vocabulary items, concordances and quotes, selected parts of relevant Wikipedia entries, commentaries etc.) which help them to understand and interpret (and in turn enjoy) the preprocessed primary texts. Note that the co-reference and/or intertextual relationships are represented, in the first place, by hypertext links between the primary texts and the supporting materials;

- second, the virtual library is intended to support language learning by carefully preparing and commenting the provided texts in order that the users, and especially the young members of the generation CE with supposed intermediate or advanced English language skills can easily acquire the accumulated knowledge and preserved values that the ancient authors created centuries ago. Although the content and structure of the virtual library focus, in the first place, on the improvement of reading as one of the four basic language skills, the first goal of the 3DVLM outlined above naturally involves the development of the learners' cultural awareness.

The learning philosophy of the model is to help the readers understand and interpret the primary texts of the virtual library 'at once', supplying them with the necessary knowledge represented by secondary materials covering the relevant linguistic or dictionary, generic, encyclopedic and background knowledge. Because the efficient (i.e. easy, simple, self-evident, user-friendly etc.) access to the primary texts and the associated secondary materials is essential in the learning process, we tried to structure, arrange and visualize the compiled material by using different and varied colors and typography (e.g. font and paragraph styles, images, graphics, icons, lists, tables, graphs, spatial maps, etc.). Note that exploiting the excellent and spectacular features of the MaxWhere 3D environment might possibly motivate the members of the generation $\mathrm{CE}$ in itself, and therefore encouraging and urging them to enhance their knowledge (being either linguistic or cultural). In addition, the importance of English language skills is undoubtedly crucial in the Internet era for everyone who wants to access and benefit from the global information sources available. Therefore we firmly hope that our potential users will, either immediately 
or eventually, make up their mind, and gradually improve their English competence in the course of reading, understanding and memorizing the preprocessed material provided by our virtual library.

We would like to provide a brief overview of similar research directions, there are several other CogInfoCom researches related to educational opportunities in virtual reality, and especially in the MaxWhere Seminar System.

- VR, in general, provides efficient virtual workspace for education even in industrial or company-based environment (e.g. dual education, VR simulations for special training etc. $[3,22])$. As "a desktop virtual environment for education, learning and working" [5], the MaxWhere Seminar System seems to be especially suitable to develop educational content in the virtual 3D space [18], and to provide personalized, customizable learning environment and paths [19].

- The MaxWhere system opens up a wide range of excellent and spectacular opportunities when we want to choose the most appropriate $3 \mathrm{D}$ space for a special application. There are several existing 3D spaces available, and new ones are being published from time to time. Due to its inherent flexibility, the system enables the development of new $3 \mathrm{D}$ environments where various objects, places, buildings, rooms etc. can be constructed or reconstructed, along with the plausible and striking arrangement of different smartboards $[17,24]$.

- According to in-depth studies, there are more benefits of the MaxWhere Seminar System. It is a substantial benefit of the 3D virtual workspace that it can display some extra information permanently for its users in designated smartboards [4]. In addition to the immersive experience that a well-designed VR environment can offer, the different navigation methods of the MaxWhere Seminar System provide a heightened sense of spatial presence for its users $[5,6]$.

- The elaborated 3D spaces of the MaxWhere system can be metaphorically considered as a "memory palace" [16] where the conceptual mapping of the various concepts of the presented content to specific parts or components of the virtual 3D environment, representing a unique spatial arrangement and/or temporal ordering of 3D objects [16], can greatly help the learners memorize the concepts, their insights, and in turn the whole material to be learned (by memorizing individual properties of the 3D objects with or without following a pre-determined scenario). Moreover, it was demonstrated by published experiments that when using MaxWhere 3D spaces for educational purposes its users have remarkably more effective memory recall, better comprehension and faster activity than using 2D web-based content [21].

All those benefits can be extensively exploited when we would like to design and create an interactive learning material in the $3 \mathrm{D}$ space. Therefore the emerging 
VR applications for educational purposes would have true potential, and they are supposed to achieve fast progress in the near future. If this is so, we can, by all means, consider "virtually augmented, interactive education" [2] in the 3D space as one of the major research areas of CogInfoCom.

In our paper we would like to focus on the data structure and organization of the current implementation of the 3DVLM. For those, who are interested in the three-dimensional virtual library model, we recommend our previous publications [7-15] where further details can be found. Note that the $2 \mathrm{D}$ version of the library is available in the internet [20].

\section{Structure patterns of the model}

The content, organization and presentation of the virtual library model are equally important for supporting efficient English language learning. In our paper we would like to focus on the data structure and organization of the virtual library model selecting, introducing and illustrating typical structure patterns by visualizing them. Each pattern follows the binary relation form $\rho(\mathrm{x}, \mathrm{y})$ where the domain $(\mathrm{X})$ and codomain $(\mathrm{Y})$ of the relation depend on the type of the pattern introduced. For example, in the simplest pattern both $\mathrm{X}$ and $\mathrm{Y}$ are sets containing primary texts (about Callimachus etc.) represented by slides and denoted by S01, S02, etc. That is,

$$
\mathrm{X} \equiv\{\mathrm{S} 01, \mathrm{~S} 02, \ldots\} \quad \text { and } \quad \mathrm{Y} \equiv\{\mathrm{S} 01, \mathrm{~S} 02, \ldots\}
$$

where the element ' $\mathrm{x}$ ' is associated to the element ' $\mathrm{y}$ ' if and only if there is a hypertext link from the slide ' $x$ ' to the slide ' $y$ '. As we shall see later, the actual representation of the link can differ according to the context (e.g. a link can be represented by a keyword or "key phrase" within the slide, a link symbol, a recommended link at the bottom of the slide etc.).

In the next subsections, we would like to introduce the most important structure patterns of the 3DVLM. We developed a kind of "navigation map" for the main items of the virtual library which can serve as a practical tool for visualizing the main patterns.

The selected items of the virtual library and the most typical relationships between them are illustrated on the interactive navigation page of the virtual library [20]. Here each item is identified by a simple code (e.g. the first slide about Callimachus is identified by S01, the second slide by S02 etc.) which are associated by a hypertext link to the exact location (e.g. an URL\#anchor) where the referred item can be found. Therefore the page actually represents a kind of "navigation map" for the main items of the virtual library (see Fig. 1).

Because each structure pattern corresponds to a given type of relationship between certain items of the library, the navigation page is a convenient way of presenting a quick overview of the main patterns. 


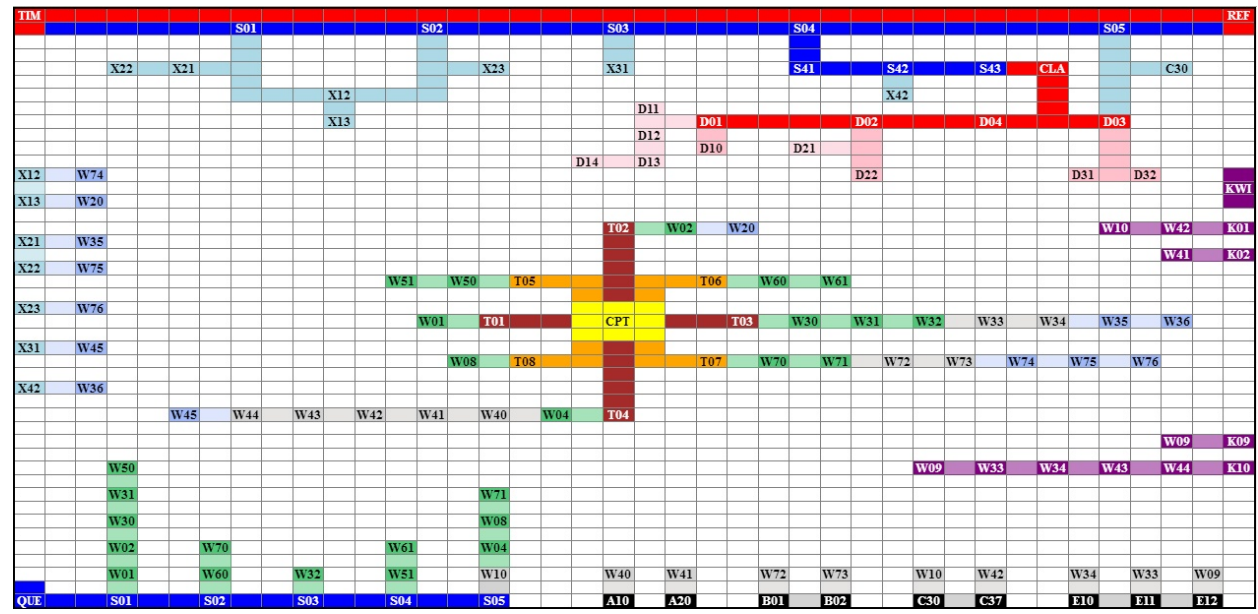

Figure 1. The navigation map of the current implementation of the 3DVLM.

\subsection{Links between primary texts [DLINK]}

This basic structure pattern represents links between primary texts presented in separate web pages or slides. As a general rule, from each slide we can step to the next slide which enables sequential access to the presented content. In the current implementation of the 3DVLM the list of primary texts (identified by S01, S02 etc.) is as follows:

- Callimachus [S01]

- Callimachus in Alexandria [S02]

- The Great Library of Alexandria [S03]

- The Pinakes [S04]

- The collection of the Great Library [S41]

- Callimachus' classification system [S42]

- The structure of the Pinakes [S43]

- The works of Callimachus [S05]

The codes of the primary texts and the relationship between them can be seen in the selected part of the navigation map of the 3DVLM (see Fig. 2).

The hypertext link is represented by the title of the linked slide (e.g. S02) placed at the bottom of the linking slide (e.g. S01), under a horizontal line (e.g. "Callimachus in Alexandria $\rightarrow$ ", see Fig. 5). 


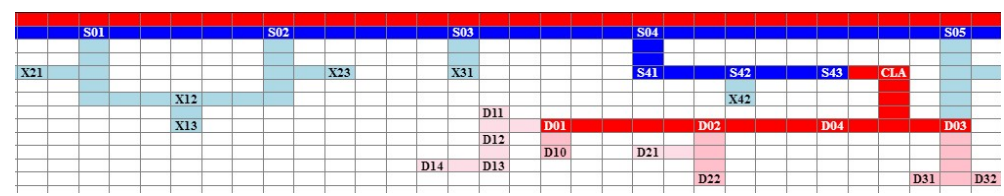

Figure 2. A selected part of the navigation map including primary texts.

\subsection{Links between primary and/or secondary texts [ELINK]}

This structure pattern represents links between primary texts and/or secondary texts (both presented in separate web pages or slides). The main function of the secondary texts is to explain certain concepts which might be unknown or unclear to an average user (that is, those texts represent encyclopedic knowledge). In the current implementation of the 3DVLM, there are slides about Cyrene (X12), Alexandria (X23), the Ptolemaic Dynasty (X21) etc. The hypertext link is represented by a special symbol (showing two parallel arrows pointing to different directions, $\rightleftarrows$ ) placed immediately after the keyword or key phrase which is associated to the linked text. In the slide about Callimachus (S01) the link symbol can be seen after Cyrene (pointing to the corresponding slide X12), the Library of Alexandria (pointing to the corresponding slide X23) etc. (see Fig. 3).

\section{CALLIMACHUS}

Callimachus (c. 310/305-c. 240 BC) * was a native of the Greek colony of Cyrene. $\#$ He was a poet, critic and scholar at the Library of Alexandria $=$ and enjoyed the patronage of the Egyptian Greek pharaohs Ptolemy II Philadelphus ("Ptolemy, lover of his sister") and Ptolemy III Euergetes ("Ptolemy the Benefactor"). $\exists$ Although he was never made chief librarian,

Figure 3. A selected part of the slide about Callimachus (S01) illustrating $\operatorname{VLINK}(\ldots)$, XLINK $(*)$ and ELINK $(\rightleftarrows)$.

\subsection{Links between slides and vocabulary items [VLINK]}

This structure pattern represents links between different kind of texts (e.g. primary texts, secondary texts, thesaurus pages etc. presented in separate slides) and vocabulary items. The main function of vocabulary items is to explain certain words (rare words, proper nouns, abbreviations etc.) which might be unknown or unclear to an average user (that is, those items represent dictionary knowledge in the usual form of dictionary entries including pronunciation, different forms, explanation etc.). The hypertext link to a vocabulary item is represented by a dotted line 
(...) under the keyword or key phrase which is associated to the linked vocabulary entry. In the slide about Callimachus in Fig. 3, the dotted link symbol can be seen under Callimachus, c., BC, native, colony, Cyrene, Alexandria, patronage etc. The vocabulary item which the uncountable noun "patronage" is associated to can be seen in Fig. 4. Note that the links to the vocabulary items, because of their quantity, are not presented in the navigation page.

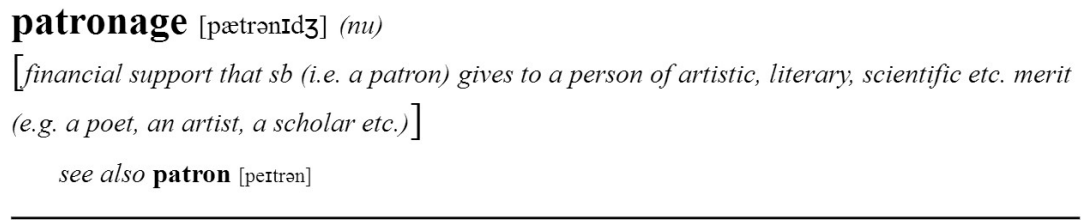

Figure 4. The vocabulary item about "patronage".

\subsection{Links between keywords (key phrases) and various notes [XLINK and CLINK]}

This structure pattern (being either XLINK or CLINK) represents links between keywords (or key phrases) and notes which might reveal some additional information (e.g. definitions, explanations, commentaries, context, pronunciation, meaning, synonyms and antonyms, sentence samples, selected concordances etc.) about the corresponding keyword or key phrase. The main difference between XLINK and CLINK is, on the one hand, the place of the note within the page where the keyword or key phrase can be found. On the other hand, in XLINK the notes have mainly explanatory function, whereas in CLINK the notes are usually background materials (revealing possible contexts etc.).

In both XLINK and CLINK, the hypertext link to the note is represented by an asterisk $(*)$ which is placed immediately after the keyword or key phrase which is associated to the corresponding note.

In the first structure pattern type (XLINK), notes are presented in the form of numbered endnotes, and placed usually in the same slide where the associated keywords can be found (although links to the notes from other slides are quite possible). In the slide about Callimachus in Fig. 3, there is an asterisk after the key phrase (c. $310 / 305$ - c. 240 BC) which is explained as "Callimachus was born around $305 \mathrm{BC}$ and died around 240 BC" in the endnote denoted by [1] (see Fig. 5).

Note that although both the explanatory notes which XLINKS point to (e.g.

[1] Callimachus was born...) and RLINKS which point to specific reference items (e.g. ... Hellenistic age. 1 and ...the Muses. 2]) are numbered in superscript position which might lead to some confusion. To avoid this, both the way we mark the numbers and their position are completely different: in case of explanatory 
notes, we use square brackets before and after the numbers, and the numbers are placed at the end of page; in case of RLINKS, however, we use border-boxes (i.e. four border edges) around the numbers and they are placed right after the content which represents a specific reference (to a given bibliographic item or source in another page).

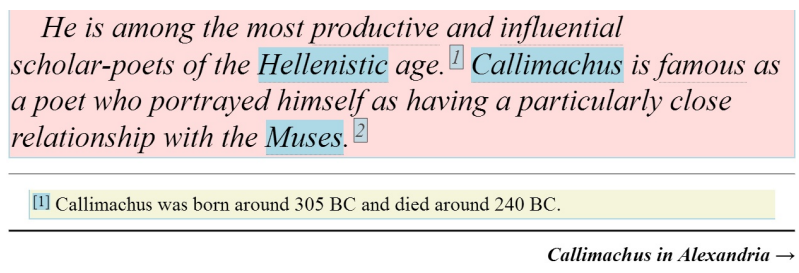

Figure 5. The note no. ${ }^{[1]}$ for (c. $310 / 305$ - c. 240 BC) illustrating XLINK the source of which can be seen in Fig. 3, represented by an asterisk $(*)$. There is a link at the bottom of the slide to another slide (entitled "Callimachus in Alexandria") illustrating DLINK.

In the second structure pattern type (CLINK), the additional information which a selected keyword or key phrase is associated to is placed immediately under the sentence or paragraph containing the keyword or key phrase. For example, in the thesaurus page (T02) the key phrase "ESL class" (emphasized by colored borders and having an asterisk as a link symbol) is associated to a short text (extracted from a web page) providing a broader context of the sentence which contains the key phrase ("In an ESL class, you would be assisting the main TEACHER who plans the lessons and is primarily responsible for the class.", see Fig. 6).

- CALLIMACHUS was responsible for producing a bibliographic survey based upon the contents of the Library. $\Rightarrow \Rightarrow$

- $\mathrm{HE}$ is responsible for designing the entire project.

- $\mathrm{HE}$ is responsible to the manager for seeing that all doors are locked at night.

- To Zeus the KINGS are responsible for $a^{\prime \prime}$ conscientious $\Rightarrow$ fulfilment of their duties.

- In an ESL class, you would be assisting the main TEACHER who plans the lessons and is primarily responsible for the class.

Volunteers are our main task force at the Refugee Development Center to volunteers do?

They provide English as a Second Language (ESL) support to adult learners in a classroom setting by In

In an ESL Class, you would be assisting the main teacher who plans the lessons and is primarily responsible for the class. You might facilitate in small groups within the classroom and help students one-on-one who need extra therested in doing so, there is flexibility for you to take greater initiative to teach parts of

lessons in front of the class, contribute ideas for teaching methods, etc. $\vec{\theta}$

Figure 6. A selected part of the thesaurus page (T02) containing concordances about "responsible for". The figure illustrates VLINK

$(\ldots), \operatorname{CLINK}(\rightleftarrows$ and $*)$, and $\operatorname{RLINK}(\Rightarrow)$.

The structure and function of thesaurus pages will be explained later in subsection 2.5 .

Where a concordance is selected from one of the primary or secondary texts it is emphasized by colored background. In such cases, the source text itself provides 
the broader context of the concordance, so it can serve as a kind of "note" (in the sense we used before) for the concordance. Although this case can also be considered as a CLINK structure pattern type, the hypertext link to the source text is represented by the same symbol that we are using in the ELINK pattern type (showing two parallel arrows pointing to different directions). For example, the first concordance in Fig. 6 (" $\boldsymbol{C A L L I M A C H U S}$ was responsible for producing a bibliographic survey based upon the contents of the Library.") can be found in the slide about Callimachus (S01) and therefore the link, presented by the sign $\rightleftarrows$ placed immediately after the concordance, is pointing to this slide.

\subsection{Links between thesaurus pages [TLINK]}

This structure pattern represents links between vocabulary items and thesaurus pages. While vocabulary entries represent dictionary knowledge, thesaurus pages represent chiefly generic knowledge (which, in our case, expressed by semantic relationships between certain words or phrases). Thesaurus pages contain a selected bunch of concordances and quotations, all of which fit a given microcontext, that is, one or two collocation patterns built of semantically related words or phrases upon a specific subject or meaning. For example, the thesaurus page (T02) is organized around words or phrases concerning "people with respect to responsibility, motivation and commitment", and the concordances or quotations in the page fit either the collocation pattern [adj + noun] or $[$ noun $+B E+\boldsymbol{a d} \boldsymbol{j} / \boldsymbol{p} \boldsymbol{p}]$ (e.g. enthusiastic person; determined woman; resolute leader; etc; He is eager, willing, and compliant to ...; Callimachus was determined not to ...; the students are ... highly motivated; Callimachus was responsible for ...; etc.). Note that we can have direct access to all thesaurus pages through the navigation map (see Fig. 1) where the corresponding codes of the thesaurus pages (T01, T02, .., T05, T06, ... etc.) can be found in the middle of the page around the code CPT (which is the abbreviation of "Collocation PaTterns", and identifies a separate web page containing all collocation patterns used in the virtual library).

As an example, let us select the first slide (S01) about Callimachus, and seek for the key sentence "CALLIMACHUS was responsible for producing a bibliographic survey based upon the contents of the Library." (W02) (see Fig. 7).

Callimachus (c. 310/305-c. 240 BC) "was a native of the
Greek colony of Cyrene. " He was a poet, critic and scholar at
the Library of Alexandria = and enjoyed the patronage of the
Egyptian-Greek pharaohs Ptolemy II Philadelphus ("Ptolemy,
lover of his sister") and Ptolemy III Euergetes ("Ptolemy the
Benefactor"). E Although he was never made chief librarian,
Callimachus was responsible for producing a bibliographic
survey based upon the contents of the Library. This, his Pinakes,
provided the foundation for later work on the history of ancient
Greek literature. E1

Figure 7. Another part of the slide about Callimachus (S01) showing the selected key sentence (W02). 
Clicking the dotted phrase "responsible for" in the page, we can go to the corresponding vocabulary page (see Fig. 8) where we can find two links to the relevant microcontexts in the corresponding thesaurus page (T02) (see Fig. 6). As we can see, the hypertext link to a thesaurus page is represented by an expression containing the key phrase "responsible for" (marked by colored background, and introduced by the symbol $\Rightarrow$ ) which is associated to the linked thesaurus page.

Note that the navigation page (see Fig. 1) shows explicitly the code of the key sentence (W02), and in turn illustrates the indirect relationship (that is, the above-mentioned two-step relationship through the corresponding vocabulary page) between the first slide (S01) and the thesaurus page (T02).

responsible [rI'spDnsabl] (for $s b / s t h)$

[having control and authority over sth/sb and the duty of taking care of it/them (Cambridge 1995)]

see also responsibility [rr,sponsə'brlati]

microcontexts:

$\Rightarrow$ responsible for producing sth

$\Rightarrow$ responsible for a conscientious fulfilment of sth

Figure 8. The vocabulary item about "responsible for" illustrating

TLINK.

\subsection{Links between various content units and reference items [RLINK]}

This structure pattern represents links between various content units from the library (that is, sentences, concordances, quotations, paragraphs, texts etc. from primary texts, secondary texts, thesaurus pages and notes) and reference items which describe the original source of the content units (printed and electronic books, journals, newspapers, Wikipedia and dictionary entries, various web pages and electronic materials available in the internet etc.). The hypertext link to a reference item is represented by either a reference number in superscript position (e.g. ${ }^{1}$ ) in slides, or a double arrow in superscript position $(\Rightarrow)$ in thesaurus pages. The link symbols are placed immediately after the corresponding content unit. For example, in the slide about Callimachus (S01) in Fig. 5 there are two references: the first is a Wikipedia entry $\left(57^{\text {th }}\right.$ item), and the second is a chapter from a book (219 th $^{\text {item}) ~(s e e ~ F i g . ~ 9) . ~}$

Another example is the concordance "In an ESL class, you would be assisting the main TEACHER who plans the lessons and is primarily responsible for the class." in the thesaurus page T02 in Fig. 6. Here the referred item is a web page (363 ${ }^{\text {rd }}$ item) (see Fig. 10).

The reference items, that is, the bibliographic descriptions of all sources having been referred to from the content of the virtual library, are available in a separate 


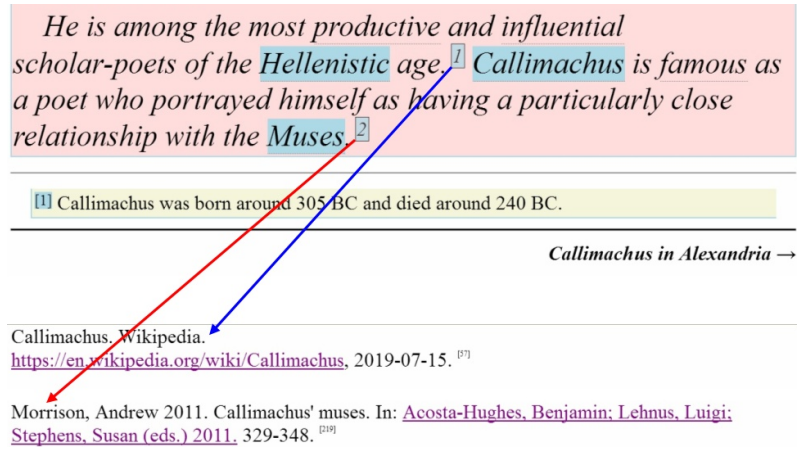

Figure 9. References from the slide about Callimachus (S01) to the $57^{\text {th }}$ and $219^{\text {th }}$ reference items illustrating RLINK.

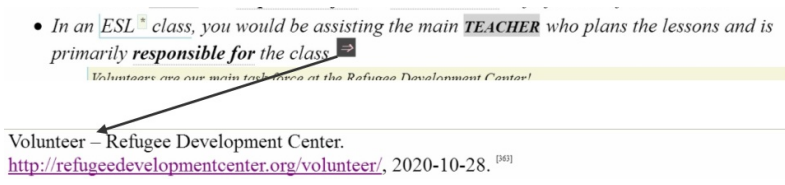

Figure 10. Reference from the thesaurus page (T02) to the $363^{\text {rd }}$ reference item illustrating RLINK.

web page $\mathrm{REF}$. In the current implementation of the 3DVLM there are more than 370 reference items. Although the code of the reference page does appear in the navigation map (in the top right corner), the individual links to the reference items are not presented there.

\begin{tabular}{|c|c|}
\hline TIME & EVENT \\
\hline \multicolumn{2}{|c|}{ c. $1260 / 1180$ BC the Trojan War Wiki } \\
\hline c. $1100 \mathrm{BC}$ & $\begin{array}{l}\text { beginning ofthe Greek Dark Ages }{ }^{\text {Wiki }} \text { (Homeric } \\
\text { Age or Geomf(tric Period) }\end{array}$ \\
\hline c. $1102 / 850 \mathrm{BC}$ & birth of Homer ${ }^{\text {(supposed) Wiki (cf.c. } 750 / 700 B C)}$ \\
\hline c. $850 / 750 \mathrm{BC}$ & $\begin{array}{l}\text { Composition of 'The Iliad' and 'The } \\
\text { Odyssey"(supposed) Wiki }\end{array}$ \\
\hline & end of the Greek Dark Ages Wiki \\
\hline
\end{tabular}

Figure 11. Reference from the top of the timeline page (TIM) to the $357^{\text {th }}$ reference item illustrating RLINK.

Although we have had a comprehensive overview of the most important structure patterns of the virtual library model, there are some additional features. For example there is a timeline page (TIM) of the most important events ("histori- 
cal milestones"), an index page of selected keywords (KWI), and a category page which describes the main categories of the hierarchical classification scheme (CLA) of the ancient Library of Alexandria. Note that this famous scheme, referred to as "Pinakes", was invented by Callimachus in the 3rd century BC. In the current implementation of the 3DVLM each content unit of those pages has a hypertext link to a selected item in the reference page (e.g. to a relevant Wikipedia entry) where additional information can be found about the content (see Fig. 11).

\section{Final remarks}

Although the current implementation of the model in the MaxWhere Seminar System uses the 3D Castle space, the model, because of its flexible organization, is fully compatible with other MaxWhere 3D spaces. In the 3D Castle space the content of the virtual library is presented in carefully arranged smartboards (see Fig. 12 and Fig. 13). With a special care we have developed the navigation map which presents the various kinds of relationships between the content units of the virtual library and thus making the retrieval of these units more effective for the users.

In our paper we provided a brief overview of how the content of the virtual library is organized. We emphasized and visualized those features of the model which might be useful for the possible users of the virtual library, focusing especially on the needs of English language learners who, we firmly hope, are going to have strong interest in and motivation about the ancient culture and heritage.

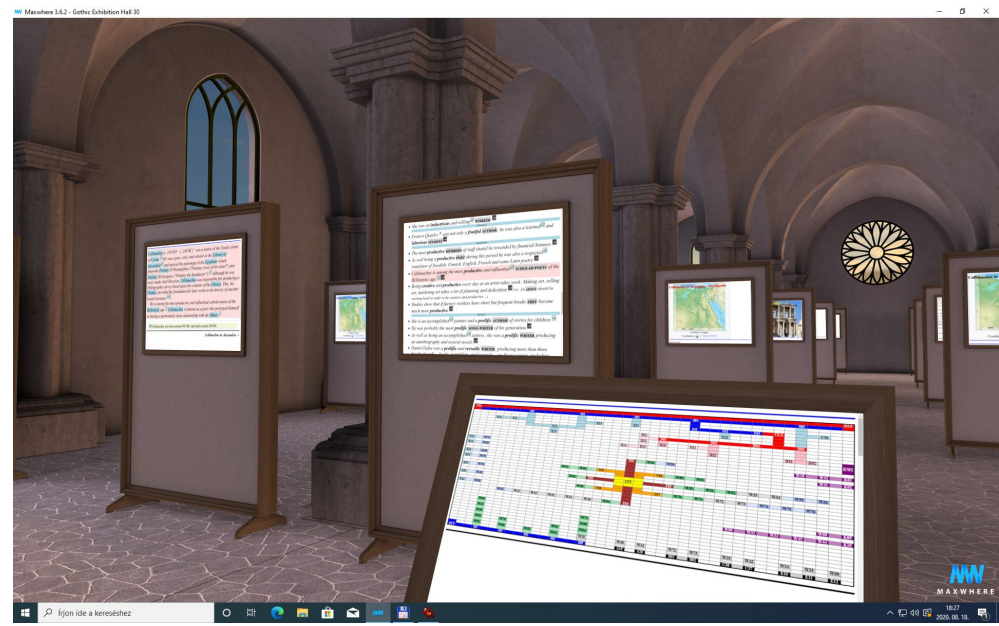

Figure 12. The content of the virtual library in the 3D Castle space of the MaxWhere Seminar System (1). 


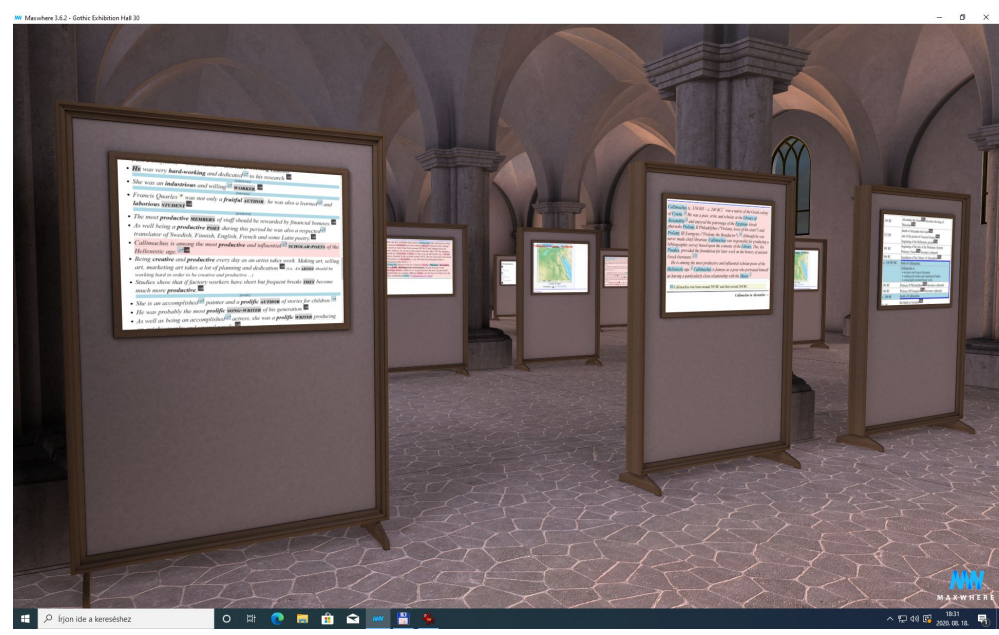

Figure 13. The content of the virtual library in the 3D Castle space of the MaxWhere Seminar System (2).

Acknowledgements. The results presented in the paper have partially been achieved in the Virtual Reality Laboratory of the Faculty of Informatics of the University of Debrecen, Hungary.

\section{References}

[1] P. Baranyi, Á. Csapó: Definition and synergies of Cognitive Infocommunications, Acta Polytechnica Hungarica 9.1 (2012), pp. 67-83.

[2] P. Baranyi, Á. Csapó, G. Sallai: Cognitive Infocommunications (CogInfoCom), Berlin, Heidelberg: Springer, 2015, DOI: https://doi.org/10.1007/978-3-319-19608-4.

[3] F. Bellalouna: Virtual-Reality-based Approach for Cognitive Design-Review and FMEA in the Industrial and Manufacturing Engineering, in: CogInfoCom 2019. Proceedings of the 10th IEEE International Conference on Cognitive Infocommunications, Piscataway, NJ, USA: IEEE, 2019, pp. 41-46, DOI: https://doi.org/10.1109/CogInfoCom47531.2019.9090002.

[4] B. Berki: Desktop VR as a Virtual Workspace: a Cognitive Aspect, Acta Polytechnica Hungarica 16.2 (2019), pp. 219-231.

[5] B. Berki: Navigation Power of MaxWhere: a Unique Solution, in: CogInfoCom 2020. Proceedings of the 11th IEEE International Conference on Cognitive Infocommunications, Piscataway, NJ, USA: IEEE, 2020, pp. 511-515, DOI: https://doi.org/10.1109/CogInfoCom50765.2020.9237904.

[6] B. Berki: Sense of Presence in MaxWhere Virtual Reality, in: CogInfoCom 2019. Proceedings of the 10th IEEE International Conference on Cognitive Infocommunications, Piscataway, NJ, USA: IEEE, 2019, pp. 91-94, DOI: https://doi.org/10.1109/CogInfoCom47531.2019.9089976. 
[7] I. Boda, M. BÉnyei, E. Tóth: New dimensions of an ancient Library: the Library of Alexandria, in: CogInfoCom2013. Proceedings of the 4th IEEE International Conference on Cognitive Infocommunications, New York, NY, USA: IEEE, 2013, pp. 537-542, DOI: https://doi.org/10.1109/CogInfoCom.2013.6719306.

[8] I. BodA, E. Tо́тн: From Callimachus to the Wikipedia: an ancient method for the representation of knowledge in the $W W W$ era, in: CogInfoCom2018. Proceedings of the 9th IEEE International Conference on Cognitive Infocommunications, Piscataway, NJ, USA: IEEE, 2018, pp. 205-210, DOI: https://doi.org/10.1109/CogInfoCom.2018.8639895.

[9] I. Boda, E. Tóth, M. BÉnyei, I. Csont: A three-dimensional virtual library model of the ancient Library of Alexandria, in: ICAI 2014. Proceedings of the 9th International Conference on Applied Informatics, Eger, Hungary: Eszterházy Károly Teacher Training College, 2014, vol. $1,103-111$, DOI: https://doi.org/10.14794/ICAI.9.2014.1.103.

[10] I. Boda, E. Tóth, I. Csont, L. T. Nagy: Developing a knowledge base of ancient literary texts in virtual space, in: CogInfoCom2016. Proceedings of the 7th IEEE International Conference on Cognitive Infocommunications, Piscataway, NJ, USA: IEEE, 2016, pp. 263-270, DOI: https:doi.org/10.1109/CogInfoCom.2016.7804559.

[11] I. Boda, E. Tóth, I. Csont, L. T. Nagy: The use of mythological content in virtual learning environment, in: CogInfoCom2017. Proceedings of the 8th IEEE International Conference on Cognitive Infocommunications, Piscataway, NJ, USA: IEEE, 2017, pp. 307-314, DOI: https://doi.org/10.1109/CogInfoCom.2017.8268262.

[12] I. Boda, E. Tóth, I. Csont, L. T. NAgy: Toward a knowledge base of literary content focusing on the ancient Library of Alexandria in the three dimensional space, in: CogInfoCom2015. Proceedings of the 6th IEEE International Conference on Cognitive Infocommunications, New York, NY, USA: IEEE, 2015, pp. 251-258, DOI: https://doi.org/10.1109/CogInfoCom.2015.7390600.

[13] I. Boda, E. Tóth, F. Z. IszÁly: Text-based approach to second language learning in the virtual space focusing on Callimachus' life and works, in: CogInfoCom 2019. Proceedings of the 10th IEEE International Conference on Cognitive Infocommunications, Piscataway, NJ, USA: IEEE, 2019, pp. 439-444, DOI: https://doi.org/10.1109/CogInfoCom47531.2019.9089933.

[14] I. K. Boda, E. Tóth: Classical Heritage and Text-Based Second Language Learning in Three-Dimensional Virtual Library Environment, in: ICAI 2020. Proceedings of the 11th International Conference on Applied Informatics, Achen, Germany: CEUR-WS, Vol. 2650., 2020, pp. 46-56.

[15] I. K. Boda, E. Tótн: English language learning in virtual 3D space by visualizing the library content of ancient texts, in: CogInfoCom2020. Proceedings of the 11th IEEE International Conference on Cognitive Infocommunications, Piscataway, NJ, USA: IEEE, 2020, pp. 305311 ,

DOI: https://doi.org/10.1109/CogInfoCom50765.2020.9237887.

[16] Á. B. Csapó, I. Horváth, P. Galambos, P. Baranyi: VR as a Medium of Communication: from Memory Palaces to Comprehensive Memory Management, in: CogInfoCom 2018. Proceedings of the 9th IEEE International Conference on Cognitive Infocommunications, Piscataway, NJ, USA: IEEE, 2018, pp. 389-394, DOI: https://doi.org/10.1109/CogInfoCom.2018.8639896.

[17] A. Gilányi, A. Rácz, A. M. Bólya, J. Décsei, K. Chmielewska: A Presentation Room in the Virtual Building of the First National Theater of Hungary, in: CogInfoCom 2020. Proceedings of the 11th IEEE International Conference on Cognitive Infocommunications, Piscataway, NJ, USA: IEEE, 2020, pp. 519-523, DOI: https://doi.org/10.1109/CogInfoCom50765.2020.9237828. 
[18] I. HoRváth: How to Develop Excellent Educational Content for 3D VR, in: CogInfoCom 2019. Proceedings of the 10th IEEE International Conference on Cognitive Infocommunications, Piscataway, NJ, USA: IEEE, 2019, pp. 483-489, DOI: https://doi.org/10.1109/CogInfoCom47531.2019.9089916.

[19] I. Honváth: Personalized Learning Opportunity in 3D VR, in: CogInfoCom 2020. Proceedings of the 11th IEEE International Conference on Cognitive Infocommunications, Piscataway, NJ, USA: IEEE, 2020, pp. 425-439, DOI: https://doi.org/10.1109/CogInfoCom50765.2020.9237895.

[20] Interactive map of the three dimensional virtual library (3DVLM), URL: https://bodaistvan.hu/callimachus/map.html (visited on 01/05/2021).

[21] D. Kiss, P. Baranyi: 3D Webspace VS 2D Website, in: CogInfoCom 2020. Proceedings of the 11th IEEE International Conference on Cognitive Infocommunications, Piscataway, NJ, USA: IEEE, 2020, pp. 517-518, DOI: https://doi.org/10.1109/CogInfoCom50765.2020.9237898.

[22] Z. Kvasznicza, J. Kovács, G. Maza, B. PÉli: VR-based Dual Education at E. ON. The Win-win-win Situation for Companies, Graduates and Universities, in: CogInfoCom 2019. Proceedings of the 10th IEEE International Conference on Cognitive Infocommunications, Piscataway, NJ, USA: IEEE, 2019, pp. 479-482, DOI: https://doi.org/10.1109/CogInfoCom47531.2019.9089961.

[23] MaxWhere VR Even more, URL: http://www.maxwhere.com/ (visited on 01/05/2021).

[24] A. Rácz, A. Gilányi, A. M. Bólya, J. Décsei, K. Chmielewska: On a Model of the First National Theater of Hungary in MaxWhere, in: CogInfoCom 2020. Proceedings of the 11th IEEE International Conference on Cognitive Infocommunications, Piscataway, NJ, USA: IEEE, 2020, pp. 575-576, DOI: https://doi.org/10.1109/CogInfoCom50765.2020.9237848. 